\title{
Inibição da resposta de hipersensibilidade do Tipo I da prole de camundongos mediada pela imunização materna com o ácaro Dermatophagoides Pteronyssinus ${ }^{\star}$
}

\author{
Inhibition of offspring Type I hypersensitivity response \\ through maternal immunization with the dust mite \\ Dermatophagoides Pteronyssinus ${ }^{\star}$
}

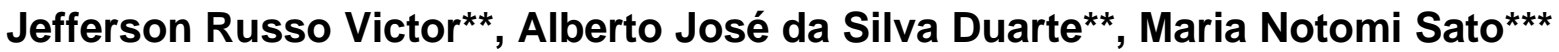

\begin{abstract}
Victor JR, Duarte AJS, Sato MN. Inibição da resposta de hipersensibilidade do Tipo I da prole de camundongos mediada pela imunização materna com o ácaro Dermatophagoides pteronyssinus. Rev Med (São Paulo) 2002 jan./dez.;81(1/ 4):22-30.

RESUMO: A exposição precoce a alérgenos associada a tendência dos neonatos a desenvolverem respostas do tipo Th2 pode contribuir com o desenvolvimento da alergia durante a infância. $O$ efeito da imunização de camundongos fêmeas $\mathrm{A} / \mathrm{Sn}$ pré concepção com o ácaro Dermatophagoides pteronyssinus (Dp), foi analisado na resposta de hipersensibilidade tipo I da prole híbrida. A cinética da imunização dos filhotes com Dp foi avaliada da idade neonatal até a adulta. As proles de mães imunes não demonstraram evidência de sensibilização pré ou pós natal ao alérgeno pela análise dos alótipos de anticorpos. A imunização com Dp das proles derivadas de mães imunizadas no período neonatal e após o desmame revelou uma significativa inibição da produção de anticorpos $\lg E$ e $\lg G 1$ anti-Dp, permanecendo diminuída mesmo após os desafios alergênicos secundários. A inibição da resposta foi específica para o Dp considerando que a imunização com antígeno heterólogo induziu similar produção de anticorpos IgE ao grupo de proles controles. A imunização materna com Dp sugere proteger o desenvolvimento precoce de alergia nos filhotes.
\end{abstract}

DESCRITORES: Camundongos; Imunização/métodos; Modelos animais de doença; Hipersensibilidade imediata/etilogia.

\section{INTRODUÇÃO}

O período neonatal é altamente suscetível a infecções virais e bacterianas e apresenta predisposição para uma expansão seletiva das células CD4+ do sub-tipo Th-2, principalmente a alérgenos. Além da influência genética para a atopia a sensibilização neonatal gerada por influência pré e/ou pós-natal, pode ser uma das causas primárias do aumento da prevalência das doenças alérgicas. Nas doenças alérgicas, é possível que a interferência da exposição a alérgenos através dos anticorpos maternos seja um mecanismo protetor essencial para a prevenção da sensibilização precoce. Os anticorpos maternos amplamente reconhecidos na proteção à várias infecções, pode essencialmente interferir na imunização ativa das crianças pelas vacinas 1,17 .

A transmissão de anticorpos maternos decorrente da imunização de camundongos fêmeas com ovalbumina e a exposição ao antígeno em fase precoce da vida podem suprimir a resposta $\operatorname{lgE}$ e $\lg G$ da prole ${ }^{9,11}$. Além disso, tem sido demonstrado que o efeito supressor da resposta $\lg E$ ao veneno de

* Prêmio Oswaldo Cruz (Área Básica) - XXI COMU Congresso Médico Universitário da FMUSP.

${ }^{* *}$ Acadêmicos da FMUSP.

*** Pesquisadora do Laboratório de Imunogenética e Transplante Experimental (orientadora).

Endereço para correspondência: Lab. Alergia e Imunologia Clínica e Experimental da FMUSP (LIM/56). Av. Dr. Arnaldo, 455, Sala 2345, $2^{\circ}$ andar, CEP: 01245-903 São Paulo, SP. 
abelha fosfolipase A2 na prole de camundongos pode ocorrer independente do antígeno e ser mediado por anticorpos IgG monoclonais maternos ${ }^{22}$. Recentemente, observamos que a imunização murina ao ácaro Dermatophagoides pteronyssinus antes da gestação pode prevenir as respostas de hipersensibilidade do tipo I devido a transferência de elevados níveis de anticorpos anti-Dp nos períodos pré e pós-natal, e por promover aumento dos níveis de TGF-b1 no leite materno ${ }^{6}$. O protocolo de imunização materna pode interferir na seleção do repertório de células $T$ e $B$ e na tendência da resposta Th2 de camundongos neonatos. Neste contexto, tem sido observado que os anticorpos maternos contribuem na formação do repertório $T$ e $B$ e na resposta humoral da prole adulta ${ }^{5-13}$. Desta forma, é fundamental verificar o efeito da exposição precoce da prole ao alérgeno, e o desenvolvimento da hipersensibilidade do tipo I, ou seja, na resposta secundária.

Neste trabalho foi analisado o efeito da imunização murina materna ao ácaro Dermatophagoides pteronyssinus (Dp) na resposta de hipersensibilidade tipo I em proles imunizadas com Dp em diferentes idades. A identificação, o tempo de permanência e a avidez dos anticorpos maternos foram avaliados nos soros das proles. A imunização primária da prole em período neonatal e a resposta secundária de anticorpos $\lg$ E e $\lg \mathrm{G} 1$, assim como a especificidade do efeito da imunização da prole com antígeno não relacionado foram avaliados.

\section{MATERIAIS E MÉTODOS}

\section{Animais}

Camundongos isogênicos $\mathrm{A} / \mathrm{Sn}$ fêmeas e C57BL/6 machos, foram utilizados com 8-10 semanas de idade. A prole (F1) obtida do acasalamento de camundongos A/Sn e C57BL/6 foi utilizada em diferentes idades. Ratos isogênicos Wistar Furth de ambos os sexos, com 3-4 meses de idade foram utilizados para as reações de anafilaxia cutânea passiva (ACP).

\section{Protocolo de imunização}

Camundongos fêmeas $\mathrm{A} / \mathrm{Sn}$ foram imunizados peł via subcutânea com $10 \mathrm{~m} \mu \mathrm{g}$ de Dermatophagoides pteronyssinus (Dp, IFIDESA-ARISTEGUI, 112.900 $\mathrm{UBE} / \mathrm{ml}$ ) em $6 \mathrm{mg}$ de hidróxido de alumínio $\left[\mathrm{Al}(\mathrm{OH})_{3}\right]$. Nove dias após a imunização, as fêmeas foram acasaladas com camundongos C57BL/6 machos não imunizados. Como grupo controle fêmeas não imunizadas foram acasaladas. As proles foram imunizadas pela via intraperitoneal (i.p.) com $10 \mathrm{m \mu g}$ de $\mathrm{Dp} / 0.61 \mathrm{mg} \mathrm{Al}(\mathrm{OH})_{3}$ aos 3 dias de idade (d-i) ou com $10 \mathrm{m \mu g} / 1,53 \mathrm{mg} \mathrm{Al}(\mathrm{OH})_{3}$ aos 25, 45 ou $90 \mathrm{~d}$-i. Após dez dias as proles receberam um reforço i.p. com 10 mug de Dp em solução salina. Os animais foram sangrados após sete dias e as amostras de soro foram congeladas a-70 $\mathrm{C}$ até o momento de uso. Alguns grupos de neonatos com $3 \mathrm{~d}$-i após a imunização, foram reforçados com 10 mðg de Dp em salina aos $13 d$-i e $35 d$-i, e sangrados sete dias mais tarde. Outros grupos de camundongos com $25 \mathrm{~d}$-i foram imunizados, reforçados i.p. com 10 mug de Dp em salina aos $35 \mathrm{~d}-\mathrm{i}, 55 \mathrm{~d}-\mathrm{i}$ e novamente aos $92 \mathrm{~d}-\mathrm{i}$, e sangrados sete dias mais tarde.

A imunização heteróloga da prole derivada de mães imunizadas com Dp ou controles foi realizada injetando-se pela via i.p. $50 \mathrm{~m} \mu \mathrm{g}$ de ovalbumina (OVA, SIGMA, St. Louis, MO, USA) $/ 0,1 \mathrm{mg} \mathrm{Al}(\mathrm{OH})_{3}$ aos $25 \mathrm{~d}$-i. Os animais receberam um reforço pela via i.p. com $50 \mathrm{~m} \mu \mathrm{g}$ de OVA em solução salina e sangrados sete dias mais tarde. Outro grupo de proles seguindo este mesmo protocolo de imunização recebeu um reforço i.p. adicional com $50 \mathrm{~m} \mu \mathrm{g}$ de OVA em salina aos $55 \mathrm{~d}$-i.

\section{Reação de anafilaxia cutânea passiva (ACP)}

A titulação de anticorpos $\lg E$ foi realizada através da reação de anafilaxia cutânea de acordo com a técnica descrita por Ovary ${ }^{18}$ e modificada por Mota e Wong ${ }^{15}$. As diluições das amostras de soros dos camundongos foram inoculadas intradermicamente em volume de $0,1 \mathrm{ml}$ no dorso de ratos previamente tricotomizados. Após 18 horas, os ratos receberam pela via intravenosa $0,5 \mathrm{mg}$ de extrato de Dp ou 0,5 mg de OVA em $1 \mathrm{ml}$ de uma solução de Azul de Evans a 0,5\%. Uma hora depois, os ratos foram sacrificados e o título do soro foi considerado como a recíproca da maior diluição do soro que apresente reação acima de $5 \mathrm{~mm}$ de diâmetro.

\section{Obtenção de soro para análise dos anticorpos transmitidos pela via transplacentária}

Camundongos fêmeas $\mathrm{A} / \mathrm{Sn}$ imunizadas, foram acasaladas com machos C57BL/6 normais e foram submetidas a cesária aos 21 dias de gestação (termo). As fêmeas foram anestesiadas e por procedimento cirúrgico sua prole foi imediatamente retirada e anestesiada para obtenção do soro dos neonatos Foi realizado um "pool" com 5 a 9 soros de neonatos obtidos de cada fêmea prenha. $O$ soro foi diluído 1:2 em solução salina estéril e armazenado a $-70^{\circ} \mathrm{C}$ até o momento de uso.

\section{Subclasses de anticorpos IgG e alótipos}

A presença de anticorpos nos soros dos 
camundongos foi analisada por ensaio imunoenzimático (ELISA). Os orifícios de microplacas de 96 orifícios (Costar, Cambridge, MA, UK) foram sensibilizados com $10 \mathrm{mg} / \mathrm{ml}$ de extrato de Dp ou $5 \mathrm{mg} / \mathrm{ml}$ de OVA em tampão carbonato-bicarbonato (TCB) $0,1 \mathrm{M}(\mathrm{pH} 9,5)$ e incubados por 1 hora a $37^{\circ} \mathrm{C}$ e por 18 horas a $4^{\circ} \mathrm{C}$. Após lavagens em PBS, as placas foram bloqueadas com PBS contendo $1 \%$ de albumina bovina fração $V$ (SIGMA, St. Louis, MO, EUA) por 1 hora a $37^{\circ} \mathrm{C}$. Em seguida, as placas foram lavadas e incubadas com diluições seriadas do soro por 1 hora a $37^{\circ} \mathrm{C}$ e 18 horas a $4^{\circ} \mathrm{C}$. Após esta etapa, foram lavadas novamente em PBS- $0,1 \%$ Tween e incubadas com anticorpos biotinilados específicos a cada subclasse de anticorpo, anti-g1 lgh ${ }^{\mathrm{a}}$, anti-g1 lgh ${ }^{\mathrm{b}}$, (PharMingen, San Diego, CA, EUA), anti-g2a $\operatorname{lgh}^{\mathrm{b}}$ (IgG2c), anti-m $\operatorname{lgh}^{\mathrm{b}}$ e incubados por 1 hora a $37^{\circ} \mathrm{C}$. Em seguida, após as lavagens, foi adicionado às placas estreptoavidina peroxidase (SIGMA, St. Louis, MO, EUA) e incubado por 30 minutos a $37^{\circ} \mathrm{C}$. Posteriormente, a atividade enzimática foi detectada pela adição de $50 \mathrm{ml}$ de TMB (Tetrametilbenzidina, SIGMA, St. Louis, MO, EUA) por no máximo 30 minutos a temperatura ambiente. A reação foi bloqueada com ácido sulfúrico $\left(\mathrm{H}_{2} \mathrm{SO}_{4}\right) 1 \mathrm{M}$ e a leitura foi realizada a $450 \mathrm{~nm}$ em leitor de microplaca de Elisa (Molecular Devices, CA, EUA).

\section{Avidez de anticorpos IgG anti-Dp}

A avidez dos anticorpos anti-Dp nos soros dos camundongos fêmeas imunizadas a termo e no soro transplacentário transmitido a prole foi analisada por ELISA, utilizando a uréia 8M como descrito por Casseb et al. ${ }^{4} \mathrm{com}$ algumas modificações. A reação de ELISA foi procedida similarmente ao descrito no item 2.5 , com exceção de que as amostras dos soros foram incubadas em duplicatas e uma das replicatas foi lavada com PBS $0,1 \%$ Tween e outra com PBS $0,1 \%$ Tween uréia $8 \mathrm{M}$. Posteriormente foram adicionado anticorpos biotinilados anti-g de camundongo e incubado com estreptoavidina peroxidase (SIGMA, St. Louis, MO, EUA) seguido e da adição de substrato TMB (Tetrametilbenzidina, SIGMA, St. Louis, MO, EUA) Após a obtenção dos valores de densidade ótica em leitor de microplaca de Elisa (Molecular Devices, CA, EUA), os percentuais de avidez de cada amostra foram calculados [(DO uréia/DO PBS) x 100].

\section{Análise estatística}

Foi utilizado o método não paramétrico MannWhitney para comparação dos grupos estudados, sendo considerado significativo quando $\mathrm{p} \leq 0.05$.

\section{RESULTADOS}

A imunização com ácaro pré-concepção não induziu sensibilização da prole de camundongos
Camundongos fêmeas $\mathrm{A} / \mathrm{Sn}$ foram imunizados pela via subcutânea com extrato de Dermatophagoides pteronyssinus $(\mathrm{Dp})$ e após 10 dias foram acasaladas com machos C57BL/6 normais. Ao fim da gestação (21 dias), foram observados elevados níveis de anticorpos IgG1 anti-Dp, comparados a outras subclasses de lgG no soro das mães imunizadas (Figura 1a).

A avidez dos anticorpos anti-Dp transmitidos verticalmente para a prole, bem como os das fêmeas a termo que foram imunizadas antes do acasalamento foi avaliado. Na Figura 1b e 1c pode-se observar que após o tratamento com uréia $8 \mathrm{M}$ na reação de ELISA, para eliminar anticorpos de baixa avidez ao antígeno, foi detectado $30 \%$ dos anticorpos anti-Dp de alta avidez nos soros das fêmeas imunizadas. Um percentual de $23,5 \%$ de anticorpos de alta avidez ao Dp foi detectado no soro transmitido pela via transplacentária à prole. Portanto, a transmissão passiva de anticorpos específicos à prole, inclui anticorpos de elevada avidez que estão presentes em níveis semelhantes no soro das mães imunes.

a. Anticorpos maternos anti-Dp
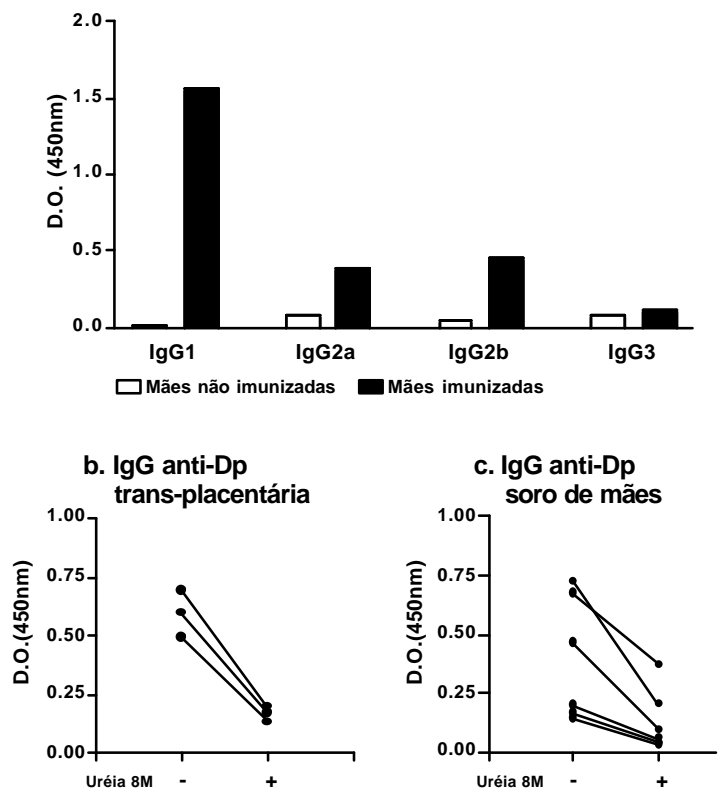

Figura 1 - Perfil das subclasses de anticorpos IgG antiDp maternos e avidez dos anticorpos específicos. Camundongos A/Sn fêmeas foram imunizados com Dp ou não e acasalados com machos C57BL/6 normais. Após 21 dias de gestação (termo) o soro das fêmeas foi coletado e um "pool" de cada grupo $(n=4)$ foi preparado, as amostras foram analisadas por ELISA quanto a presença de (a) anticorpos IgG1 (1:800), IgG2a (1:100), IgG2b (1:100) e IgG3 anti-Dp (1:25). As barras representam a média \pm DP de cada grupo. A avidez dos anticorpos IgG anti-Dp foi avaliada por ELISA (b) nos "pools" de soro transmitido pela via transplacentária ( $n=3,1: 100)$ e (c) no soro das mães imunizadas a termo no $34^{\circ}$ dia após a imunização $(n=6,1: 24300)$. Os pontos representam a densidade ótica de cada amostra com ou sem o tratamento com uréia $8 \mathrm{M}$. 
A presença de anticorpos maternos pode ser observada pela detecção de anticorpos IgG1 antiDp de alótipo lgha (alótipo materno) no soro da prole não imunizada (Figura 2a). Elevados níveis de lgG1 anti-Dp foram observados na prole com três semanas de idade, que declinou gradualmente até as nove semanas, desaparecendo em 12 semanas de idade. Anticorpos IgG1 anti-Dp de alótipo $\operatorname{lgh}^{\mathrm{b}}$ (alótipo da prole) não foram detectados nas proles provenientes de mães imunizadas (Figura 2a).

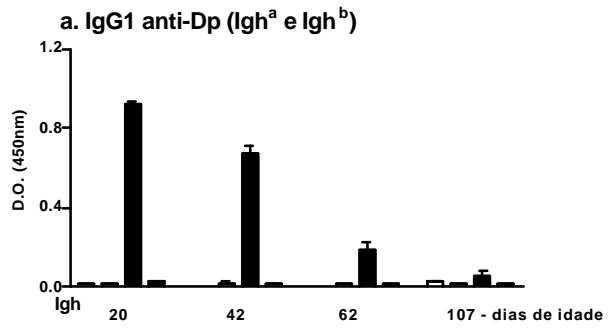

b. $\lg M$ anti-Dp $\left(\operatorname{lgh}^{b}\right)$

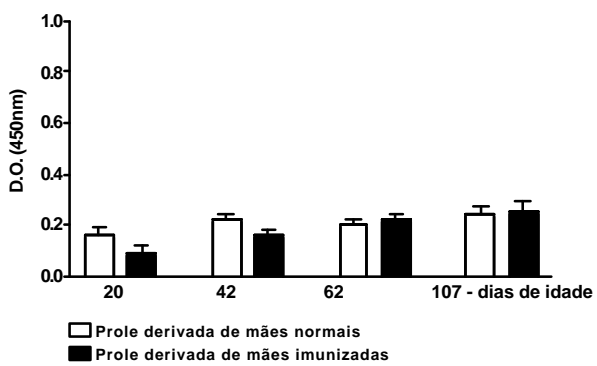

Figura 2- Evidência da imunização pré-concepção ao Dp na sensibilização da prole. Camundongos A/Sn fêmeas foram imunizados com $D p$ ou não $e$ acasalados com machos C57BL/6 normais. 0 soro da prole híbrida foi avaliado em diferentes idades quanto a presença de (a) alótipos de anticorpos IgG1 anti-Dp (lgh ${ }^{\mathrm{a}}$ e $\operatorname{lgh}^{\mathrm{b}}$ - $\mathrm{n}=7-14$ animais por grupo, 1:25), e (b) IgM anti-Dp $\left(\operatorname{lgh}^{\mathrm{b}}-\mathrm{n}=7-15\right.$ animais por grupo, 1:10) por ELISA. As barras representam a média $\pm D P$ de cada grupo.

Para avaliarmos a ocorrência de sensibilização da prole ao Dp devido a imunização materna, investigamos a presença de anticorpos IgM anti-Dp de alótipo $\operatorname{lgh}^{\mathrm{b}}$, no soro da prole não imunizada derivada de mães imunizadas com Dp. Este alótipo de anticorpos define a produção de anticorpos da prole distinguindo desta forma o alótipo de anticorpos maternos. Nenhuma evidência de anticorpos $\operatorname{lgM}^{\mathrm{b}}$ anti-Dp foi detectada nos soros das proles em diferentes idades, indicando que não ocorre sensibilização dos filhotes de mães imunizadas com Dp seja no período pré ou pós natal (Figura 2b). Além disto, a imunização materna não induziu a produção de anticorpos $\lg E$ anti-Dp analisados pela reação de anafilaxia cutânea passiva no soro das proles não imunizadas.

Produção de anticorpos IgE e subclasses de IgG na prole imunizada com Dp em várias idades

Para analisarmos a influência da exposição materna ao alérgeno na resposta de hipersensibilidade do tipo I da prole, foi analisado na cinética de imunização com $\mathrm{Dp}$ em proles de mães imunizadas ou não com Dp (Figura 3). A imunização precoce foi realizada em proles com 3 dias de idade (d-i), e após reforço aos 21 dias de idade, os filhotes de ambos os grupos de mães, não foram capazes de produzir anticorpos $\lg \mathrm{E}$ anti-Dp. As proles imunizadas aos $25 \mathrm{~d}$-i produziram anticorpos $\mathrm{IgE}$ específicos em níveis similares entre os grupos. A imunização com Dp aos $45 \mathrm{~d}$-i, promoveu uma elevação dos níveis de anticorpos $\operatorname{lgE}$ anti-Dp nas proles de mães não imunizadas e uma significativa inibição dos anticorpos na prole de mães imunizadas. A imunização aos $90 \mathrm{~d}-\mathrm{i}$ induziu uma baixa resposta $\lg \mathrm{E}$ anti-Dp nas proles derivadas de ambos os grupos de mães.

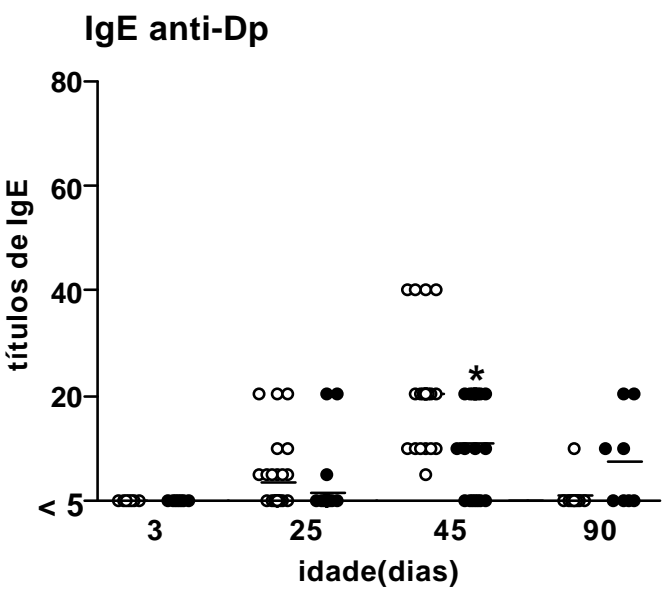

$\square$ Prole derivada de mães normais
$\square$ Prole derivada de mães imunizadas

Figura 3 - Produção de anticorpos IgE anti-Dp de proles imunizadas em diferentes idades. Camundongos A/ Sn fêmeas foram imunizados com Dp ou não e acasalados com machos C57BL/ 6 normais. As proles híbridas foram imunizadas aos 3, 25, 45 ou 90 dias de idade ( $n=10-30$ animais por grupo) e os soros foram avaliados quanto a presença de anticorpos IgE antiDp por reação de anafilaxia cutânea passiva. Na figura estão representados os títulos obtidos de cada animal e a média de cada grupo. ${ }^{*}=p \leq 0.05$ quando comparados ao grupo derivado de mães não imunizadas.

Na Figura 4a podemos observar que no grupo das proles imunizadas em período precoce $(3 \mathrm{~d}-\mathrm{i})$ de mães imunizadas, foram evidenciados somente os anticorpos de alótipo $\lg \mathrm{G}^{\mathrm{a}}$ anti-Dp. Nas proles imunizadas aos $25 \mathrm{~d}-\mathrm{i}$, derivadas de mães imunes, foi observado uma significativa inibição dos alótipos de $\operatorname{lgG} 1$ ( $\operatorname{lgh}{ }^{\mathrm{a}}$ e $\operatorname{lgh}{ }^{\mathrm{b}}$ ) anti-Dp em relação ao grupo 
derivado de mães controles. O resultado de que os níveis de anticorpos IgG1 de ambos os alótipos estarem diminuídos, indica alteração de ambas as populações de anticorpos, o alótipo de anticorpo produzido pela prole e o transmitido passivamente pela mãe. A resposta

a. $\lg G 1$ anti-Dp $\left(\operatorname{lgh}^{\mathrm{a}}\right.$ e $\left.\operatorname{lgh}^{\mathrm{b}}\right)$

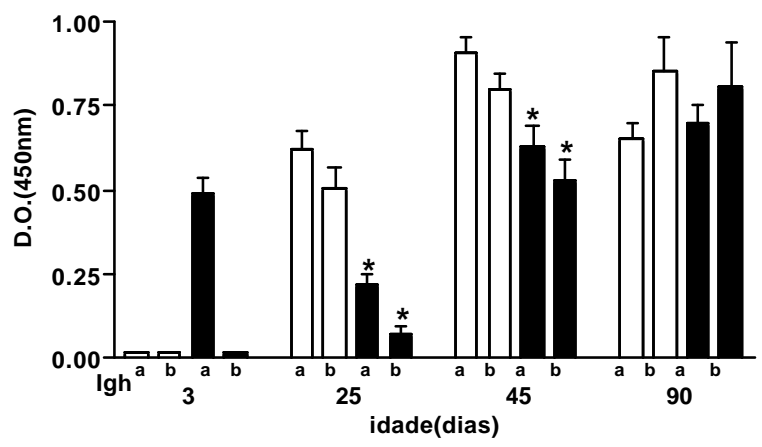

b. IgG2c anti-Dp

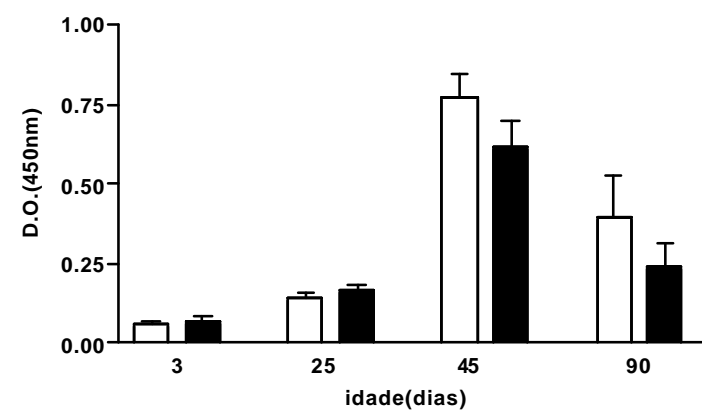

$\square$ Prole derivada de mães normais
$\square$ Prole derivada de mães imunizadas

Figura 4 - Produção de anticorpos IgG1 e lgG2c das proles imunizadas com Dp em diferentes idades. Camundongos A/Sn fêmeas foram imunizados com Dp ou não e acasalados com machos C57BL/6 normais. As proles híbridas foram imunizadas aos $3,25,45$ ou 90 dias de idade $(n=10-30$ animais por grupo) e os soros foram avaliados quanto a presença de (a) anticorpos $\lg G 1$ (Igh $\left.{ }^{\mathrm{e}} \operatorname{lgh}^{\mathrm{b}}, 1: 100\right)$ e (b) $\lg \mathrm{G} 2 \mathrm{c}(1: 20)$ por ELISA. As barras representam a média \pm DP de cada grupo. *=p£0.05 quando comparados ao grupo de mães não imunizadas.

A cinética de produção de anticorpos lgG2c antiDp da prole demonstrou um perfil similar nos grupos de proles de mães imunes e controles (Figura 4b). Baixos níveis de anticorpos IgG2c anti-Dp foram detectados nos grupos imunizados aos 3 e $25 \mathrm{~d}-\mathrm{i}$, atingindo um pico de produção do isótipo de anticorpo nos grupos imunizados aos $45 \mathrm{~d}$-i que diminuiu nos grupos imunizados aos $90 \mathrm{~d}$-i.

Permanência da inibição da produção de anticorpos da prole na resposta secundária

A influência da imunização materna também foi avaliada na resposta secundária ao $\mathrm{Dp}$. As proles imunizadas em idade neonatal (3d-i) ou jovem (25d-i) foram submetidas a desafios posteriores com Dp. Os neonatos imunizados com Dp aos $3 \mathrm{~d}-\mathrm{i}$ receberam dois reforços i.p., um aos $10 \mathrm{~d}$-i e posteriormente outro aos $35 \mathrm{~d}$-i e analisados aos 42 d-i. A imunização primária não induziu níveis detectáveis de anticorpos nesta idade, contudo, com os reforços a prole de mães imunizadas revelou uma significativa queda da resposta IgE anti-Dp em relação ao grupo de proles de mães controle (Figura 5a). Além disso, a prole de mães imunes demonstrou diminuição dos níveis de anticorpos IgG1 de ambos os alótipos $\operatorname{lgh}^{\text {a }}$ e $\operatorname{lgh}^{\mathrm{b}}$ (Figura 5b). Estes achados demonstram que a imunização materna com $\mathrm{Dp}$ pode interferir precocemente na resposta $B$ da prole, o qual posteriormente refletiu na resposta secundária. A inibição da produção do alótipo $\operatorname{lgh}^{\mathrm{b}}$, produzido pela prole, foi mais pronunciada considerando que os anticorpos maternos de alótipo $\operatorname{lgh}^{\mathrm{a}}$ ainda permanecem no soro das proles aos $42 \mathrm{~d}$-i. 


\section{a. IgE anti-Dp}

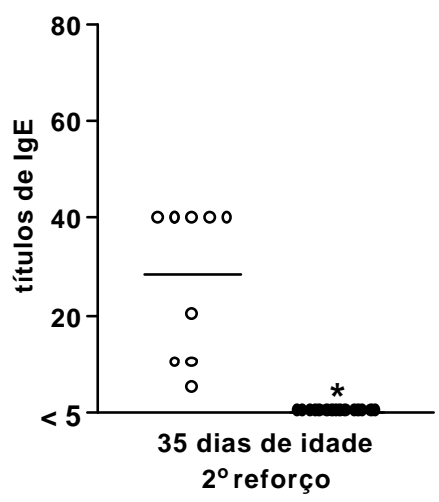

b. IgG1 anti-Dp

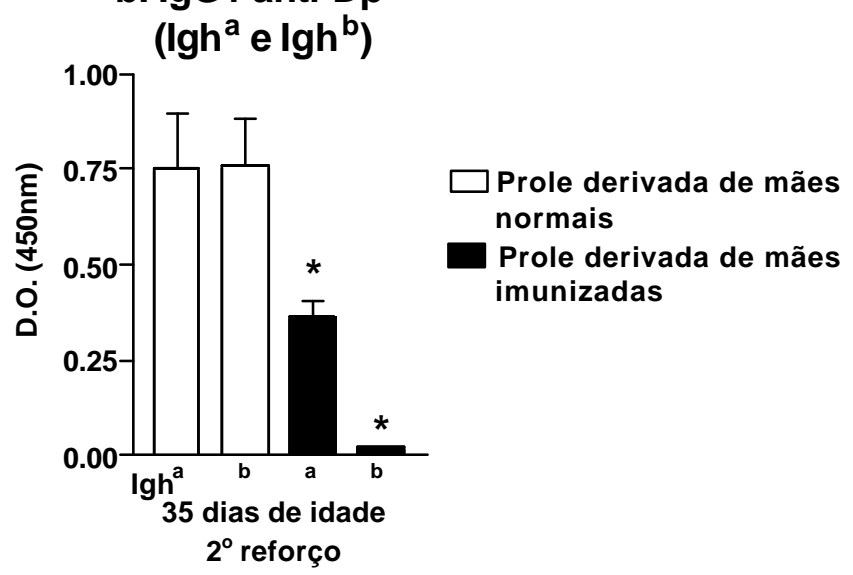

Figura 5a,b - Efeito da resposta secundária ao Dp da prole imunizada em período neonatal ou jovem. $(a, b)$ as proles de mães imunizadas com Dp ou não foram imunizadas com Dp aos 3 d-i e reforçadas via i.p. com Dp aos 10 e 35 d-i e analisadas sete dias após o último reforço

O efeito da imunização secundária com Dp também foi observado nas proles imunizadas aos 25 d-i. A imunização secundária foi realizada com dois reforços i.p. com Dp aos 35 e 55 d-i ou com três reforços realizados aos 35,55 e $92 \mathrm{~d}$-i. As proles de mães imunes ou não imunes produziram níveis similares de anticorpos lgE anti-Dp após os reforços (Figura 5c). Em contraste, a produção de anticorpos lgG1 anti-Dp de ambos os alótipos lgh ${ }^{\mathrm{a}}$ e $\operatorname{lgh}^{\mathrm{b}}$ da prole de mães imunizadas permaneceu inibida similarmente ao observado na resposta primária (Figura $5 \mathrm{~d}$ ).

\section{c. IgE anti-Dp}

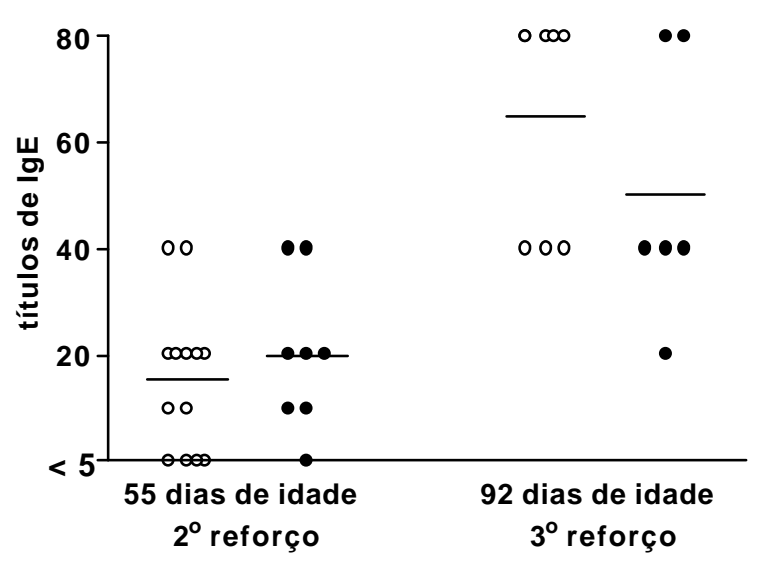

\section{d. $\lg G 1$ anti-Dp $\left(\operatorname{lgh}^{\mathrm{a}}\right.$ e $\left.\operatorname{lgh}^{\mathrm{b}}\right)$}

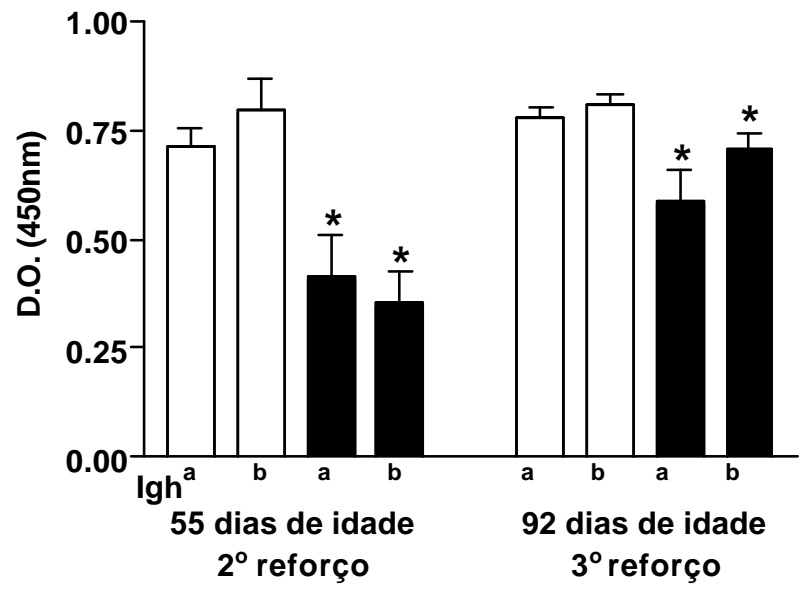

Figura $5 c, d$ - As proles foram imunizadas com Dp aos 25 d-i e reforçados via i.p. em três períodos (35, 55 e 92 di) e analisadas sete dias após o segundo e terceiro reforços.

Efeito da imunização heteróloga da prole derivada de mães imunizadas com Dp

Para verificarmos a especificidade do efeito inibitório observado na imunização materna com Dp na resposta de anticorpos da prole, os animais foram imunizados com um antígeno não relacionado, a ovalbumina (OVA). A produção de anticorpos IgE anti-OVA foi similar em ambos os grupos, mesmo com o reforço antigênico aos 55 d-i (Figura 6a). Contudo, a imunização da prole com OVA induziu um aumento da produção de anticorpos IgG1, IgM e lgG2c anti-OVA da prole de mães imunizadas com Dp (Figuras 6b, 6c e 6d, respectivamente). Este efeito foi transitório uma vez que o grupo de proles das mães imunizadas obtiveram resposta secundária similar ao grupo controle. 
a. IgE anti-OVA

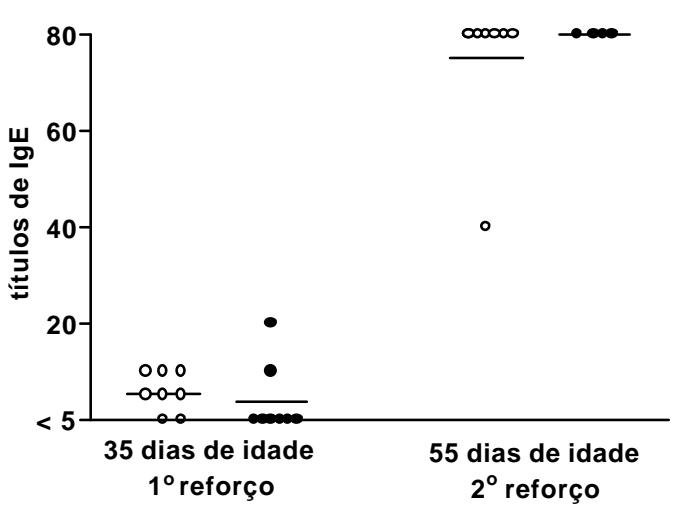

c. IgG1 anti-OVA

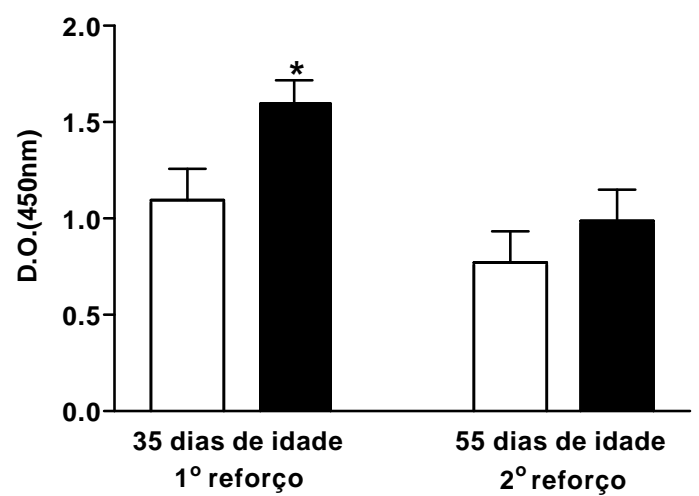

Prole derivada de mães normais

Prole derivada de mães imunizadas b. IgM anti-OVA

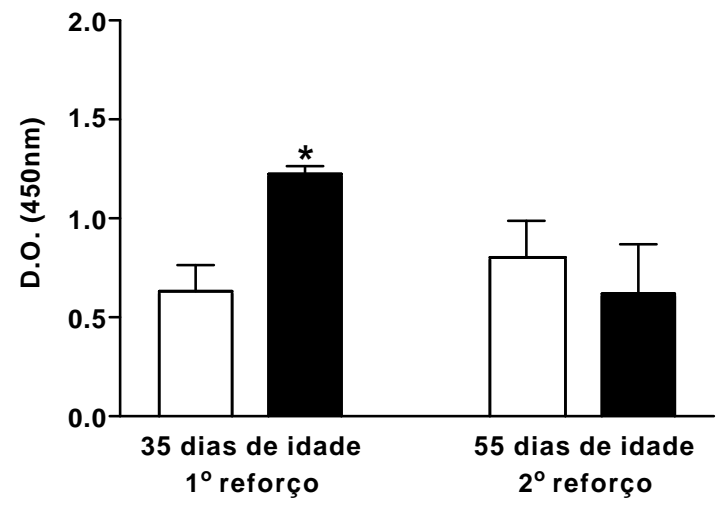

d. IgG2C anti-OVA

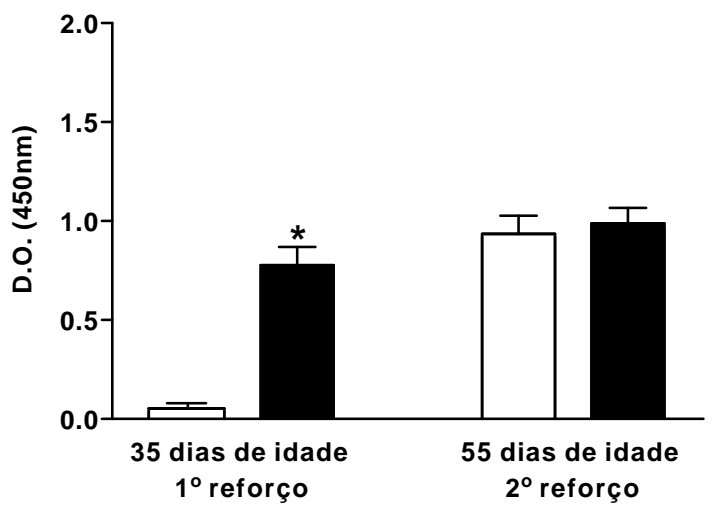

Figura 6 - Efeito da imunização heteróloga da prole de mães imunizadas com Dp. As proles de mães imunizadas com Dp ou não foram imunizadas aos 25 d-i com OVA e reforçados via i.p. aos 35 e 55 d-i ( $n=5-8$ animais por grupo). Os soros obtidos sete dias após cada reforço foram analisados quanto a presença de (a) anticorpos IgE anti-OVA por reação de anafilaxia cutânea passiva e (b) IgG1 (1:25), (c) IgG2c (1:10) e (d) IgM (1:25) anti-OVA por ELISA. As barras representam a média \pm DP de cada grupo. ${ }^{*}=p \leq 0.05$ quando comparados ao grupo derivado de mães não imunizadas.

\section{DISCUSSÃO}

A imaturidade imunológica do neonato e o grau de exposição aos alérgenos em período precoce da vida são fatores de risco para o desenvolvimento de reações alérgicas. Neste estudo foi observado que a imunização materna com o ácaro Dermatophagoides pteronyssinus (Dp) antes do acasalamento, previne a resposta de hipersensibilidade do tipo I da prole de camundongos.

Além disso, a inibição da produção de anticorpos específicos da prole manteve-se nas respostas secundárias e terciárias ao Dp. A especificidade do efeito inibitório observado nas proles imunizadas com $\mathrm{Dp}$, foi observada com a imunização primária com OVA que não afetou a resposta IgE e gerou um aumento transitório na produção de anticorpos lgG.

Os determinantes alotípicos, $\lg \mathrm{M}^{\mathrm{b}}$ e $\lg \mathrm{G} 1^{\mathrm{b}}$ antiDp, foram utilizados para distinguir a produção de anticorpos da prole, pois os anticorpos transmitidos pela mãe permanecem no soro da prole até 9 semanas de idade. Os camundongos de mães imunizadas não foram capazes de produzir anticorpos anti-Dp nos períodos analisados. Este resultado sugere que o protocolo de imunização materna realizado pela via subcutânea com Dp não foi capaz de sensibilizar os neonatos ao alérgeno, seja em 
período pré ou pós natal. A sensibilização dos neonatos pode estar relacionada ao tempo, via e intensidade da exposição materna ao alérgeno ${ }^{15,16}$ sendo necessárias maiores investigações para elucidarmos a ocorrência de sensibilização durante a vida intra-uterina. Em humanos, a evidência in vitro de resposta proliferativa de células do cordão umbilical a alérgenos inalantes ou alimentares tem sido sugerida como evidência de sensibilização in utero ao antígeno ${ }^{17,18}$. Porém, existem controvérsias de que a proliferação ou secreção de citocinas in vitro de células de cordão umbilical pode ser resultado da diversidade imune do feto ou devido a baixa sensibilidade do método utilizado, e não com a exposição in utero ao alérgeno ${ }^{19}$.

A imunização materna com Dp foi capaz de transferir anticorpos pré-natalmente, ou seja pela via placentária, de elevada avidez ao alérgeno. É possível que a seleção da população dos anticorpos transmitidos para os filhotes, seja decorrente do nível sérico de anticorpos observado nas mães imunizadas. Neste contexto, um nível semelhante de avidez dos anticorpos específicos foram observados no soro das mães e os transferidos pela via transplacentária para os filhotes.

A cinética de imunização com Dp das proles revelou que os neonatos imunizados aos três dias de idade não foram capazes de produzir anticorpos $\lg \mathrm{E} e$ lgG1 anti-Dp, provavelmente pela sua conhecida relativa imaturidade imunológica ${ }^{20,21}$. Os neonatos são deficientes na regulação positiva da expressão de moléculas de classe II do Complexo Principal de Histocompatibilidade, na condução de sinais aos receptores de células T e na expressão do CD40L, eventos necessários para uma efetiva interação de células $T-B^{22,23}$. A imunização da prole no período de desmame (25 dias de idade), ocasião em que elevados níveis de anticorpos maternos eram detectados nos soros das proles, induziu uma significativa diminuição de ambos os alótipos de lgG1. Aos 45 dias de idade, período em que a prole já adquiriu competência imunológica para produzir anticorpos antígenos $\mathrm{T}$ dependentes, foi detectada importante inibição da produção de anticorpos $\lg G 1$ e também de $\lg E$ anti-Dp. Jarrett et al. ${ }^{4,5}$ descreveram que ratos fêmeas imunizadas com ovalbumina (OVA) transmitem anticorpos que exercem efeito inibitório na resposta de $\lg E$, e aumento da produção de $\lg G$ na prole imune. Posteriormente, os autores evidenciaram que a supressão de ambas as respostas $\lg E$ e $\lg G$, depende do protocolo de imunização materna, ou seja, da dose do antígeno, uso de adjuvante e via utilizada ${ }^{6}$.

Os camundongos $\mathrm{A} / \mathrm{Sn}$ imunizados com 90 dias de idade possuem uma capacidade reduzida de produzir anticorpos IgE quando comparados aos imunizados no período pós-amamentação. É possível que o desaparecimento do efeito inibitório na resposta de anticorpos com a imunização com Dp na vida adulta seja simultâneo ao desaparecimento dos anticorpos maternos no soro. Contudo, quando as proles são imunizados precocemente e submetidas à resposta secundária ocorre uma inibição completa da produção de anticorpos $\lg E$ anti-Dp. Apesar da relativa deficiência da produção de anticorpos anti-Dp na resposta primária no período neonatal, isto parece interferir no desenvolvimento das futuras respostas de hipersensibilidade. A produção de anticorpos lgG1 da prole permaneceu intensivamente diminuída, mesmo após os reforços secundário e terciário com Dp. Um dos mecanismos propostos para o efeito inibitório dos anticorpos maternos na prole é a neutralização do antígeno, como também por modulação negativa direta das células $B$ dos neonatos através dos receptores para a porção Fc da cadeia gama. Isto implicaria na transferência de anticorpos maternos idiotípicos ou anticorpos regulatórios que poderiam influenciar 0 repertório $B$ dos neonatos durante seu desenvolvimento.

A imunização materna com $\mathrm{Dp}$, medeia uma inibição específica da resposta alérgica da prole, pois a imunização com OVA não alterou a resposta lgE anti-OVA dos filhotes. Além disso, foi verificado um aumento dos anticorpos IgG1, IgG2c e IgM anti-OVA na prole de mães imunizadas com Dp, na resposta primária a OVA. Tem sido descrito que a prole de mães imunizadas com OVA antes do acasalamento e submetidas a nebulizações com o antígeno durante toda a gestação, imunizada com antígeno heterólogo (bð-lactoglobulina) desenvolve um aumento da produção de anticorpos IgG1 e diminuição da produção de IFN-g ${ }^{15,16}$. A hipótese de que a maturação tardia da imunidade Th1 da prole de mães alérgicas predispõe o desenvolvimento de alergias a novos antígenos, pode exercer um importante impacto sobre as doenças alérgicas. Nossos resultados demonstram que a imunização com Dp induz uma inibição da resposta a anticorpos de forma específica sem interferir na resposta IgE a antígenos heterólogos. Entretanto, diferentemente ao efeito inibitório observado com a imunização com Dp a resposta IgG a OVA parece ser transitória. É possível que o aumento dos níveis primários da resposta de anticorpos IgG anti-OVA esteja relacionado ao desequilíbrio da produção de citocinas pela prole, mas que não se perpetua na reposta secundária.

A imunização materna com Dp induziu uma significativa inibição da produção de anticorpos da prole, mantendo este efeito nas respostas secundária e terciária ao $\mathrm{Dp}$. Os resultados indicam que a imunização materna, induz um efeito protetor à prole, de forma específica, e que interferem no repertório das células B e T. Desta forma, a imunização com Dp préconcepção, parece ser benéfica impedindo a sensibilização precoce da prole ao alérgeno, e sugere ser uma estratégia profilática ao desenvolvimento da resposta alérgica. 
Victor JR, Duarte AJS, Sato MN. Inhibition of offspring Type I hypersensitivity response through maternal immunization with the dust mite Dermatophagoides pteronyssinus. Rev Med (São Paulo) 2002 jan./dez.;81(1/4):22-30.

ABSTRACT: The early life exposure to allergens associated with the tendency of newborns to develop Th2-biased responses, may contribute to the development of allergy during infancy. The effect of preconception immunization of A/ Sn females with the dust mite Dermatophagoides pteronyssinus (Dp), were analysed on the hybrid offspring's type I hypersensitivity response. The kinetics of Dp immunization was followed from newborn to adult age. Offspring from immune mothers did not show evidence of pre or postnatal allergen priming at humoral level. Immunization with $\mathrm{Dp}$ in very early life and in the postweaning period revealed a marked inhibition of offspring anti-Dp IgE and IgG1 Ab production, which remained decreased upon secondary allergenic challenge. The maternal influence on the offspring's Ab response was specific to $\mathrm{Dp}$, since their immunization with a heterologous antigen led to a normal lgE response. Taken together, maternal immunization to $\mathrm{Dp}$ seems to be protective in regard to the early development of allergy.

KEYWORDS: Mice; Immunization/methods; Disease models, animal; Hipersensitivity, immediate/etiology.

\section{REFERÊNCIAS}

1. Albrecht P, Ennis FA, Saltzmann EJ, Krugman S. Persistence of maternal antibody in infants beyond 12 months: mechanisms of measles vaccine failure. J Pediatr 1977;91:715-8.

2. Astori M, Finke D, Karapetian O, Acha-Orbea $\mathrm{H}$. Development of T-B cell collaboration in neonatal mice. Int Immunol 1999;11:445-51.

3. Bona C, Bot A. Neonatal immuno-responsiveness. Immunologist 1997;5:5-9.

4. Casseb J, Katzenstein D, Winters M, Brigido LFM, Duarte AJS, Hendry RM. Serotyping HIV-1 with V3 peptides: detection of high avidity antibodies presenting clade-specific reactivity. Braz J Med Biol Res 2002;35:369-75.

5. Elliot M, Kearney JF. Idiotypic regulation of development of the B-cell repertoire. Ann N Y Acad Sci 1992;651:336-45.

6. Fusaro AE, Maciel M, Victor JR, Oliveira CR, Duarte AJS, Sato MN. Influence of maternal murine immunization with Dermatophagoides pteronyssinus extract on the type I hypersensitivity response in offspring. Int Arch Allergy Immunol 2002;127(3):20816.

7. Herz U, Joachim R, Ahrens B, Scheffold A, Radbruch A, Renz H. Allergic sensitization and allergen exposure during pregnancy favor the development of atopy in the neonate. Int Arch Allergy Immunol 2001;124:1936.

8. Herz U, Ahrens B, Scheffold A, Joachim R, Radbruch A, Renz H. Impact of in utero Th2 immunity on T cell deviation and subsequent immediate-type hypersensitivity in the neonate. Eur J Immunol 2000;30:714-8.

9. Jarrett E, Hall E. Selective suppression of IgE antibody responsiveness by maternal influence. Nature 1979; 280:145-7.

10. Jarrett $E$, Hall E. IgE suppression by maternal IgG. Immunology 1983;48:49-58.

11. Jarrett $E$, Hall $E$. The development of IgE-suppressive immunocompetence in young animals: influence of exposure to antigen in the presence or absence of maternal immunity. Immunology 1984;53:365-73.

12. Lemke $H$, Lange $H$, Berek $C$. Maternal immunization modulates the primary immune response to 2phenyl-oxaxolone in BALB/c mice. Eur J Immunol 1994;24:3025-30.
13. Lundin BS, Dahlman-Höglund A, Pettersson I, Dahlgren UIH, Hanson LA, Telemo E. Antibodies given orally in the neonatal period can affect the immune response for two generations: Evidence for active maternal influence on the newborn's immune system. Scand J Immunol 1999;50:651-6.

14. Marshall-Clarke S, Reen D, Tasker L, Hassan J. Neonatal immunity: how well has it grown up? Immunol Today 2000;21:35-41.

15. Mota I, Wong D. Homologous and heterologous passive cutaneous anaphylactic activity of mouse antisera durin the course of immunization. Life Sci $1969 ; 8(16): 813-20$.

16. Murphy BR, Olmsted RA, Collins PL, Chanock RM, Prince GA. Passive transfer of respiratory syncytial virus (RSV) antiserum suppresses the immune response to the RSV fusion $(F)$ and large $(G)$ glycoproteins expressed by recombinant vaccinia viruses. J Virol 1988;62: 3907-10.

17. Osborn JJ, Dancis J, Julia JF. Studies of the immunology of the newborn infant. II Interference with active immunization by passive transplacental circulating antibody. Pediatrics 1952;10:328-34.

18. Ovary Z. Passive cutaneous anaphylaxis in the mouse. J Immunol 1958;81:325-8.

19. Platts-Mills TAE. Cord blood proliferative responses to inhaled allergens: Is there a phenomenon? J Allergy Clin Immunol 2000;106:441-3.

20. Prescott ST, Holt PG, Jenmalm M, Bjorkstéin B. Effects of maternal alergen-specific lgG in cord blood on early postnatal development of allergen-specific T-cell immunity. Allergy 2000;55:470-5.

21. Prescott SL, Macaubas C, Holt BJ, Smallacombe TB, Loh R, D Sly P, Holt PG. Transplacental priming of the human immune system to environmental allergens: Universal skewing of initial T cell responses toward the Th2 cytokine profile. J Immunol 1998;160:47307.

22. Seeger M, Hermann-JT, Lange $H$, Shaw L, Hansen $H$, Lemke $\mathrm{H}$. Antigen-independent suppression of the $\lg \mathrm{E}$ immune response to bee venom phospholipase A2 by maternally derived monoclonal IgG antibodies. Eur J Immunol 1998;28:2124-30.

23. Tasker L, Marshall Clarke S. Immature B cells from neonatal mice show a selective inability to up-regulate MHC class II expression in response to antigen receptor ligation. Int Immunol 1997;9:475-84. 